\section{Yucca Mountain, deemed safe, still faces long road ahead}

\begin{abstract}
A lmost four years after the Obama administration shut down the Yucca Mountain nuclear waste repository project, a new report released in October 2014 by the US Nuclear Regulatory Commission (NRC) has put Yucca Mountain in the news again.

The report is Volume 3 of the five-volume safety evaluation report required for the NRC's license application review for the geological repository. This volume, which addresses safety after permanent closure, concludes that the repository will meet regulatory requirements after it is permanently closed. In essence, the NRC expects that the repository, because of the multiple natural and engineered barriers it employs, should be able to withstand human intrusion and isolate high-level radioactive waste from the environment for up to a million years.

Volume 3 is based on a thorough, sound technical assessment and is a win for science, said Rodney McCullum, director of used fuel programs at the Nuclear
\end{abstract}

Engineering Institute, a nuclear industry lobbying group in the United States. However, according to Rod Ewing, ${ }^{*}$ a professor in the School of Earth Sciences at Stanford University, the release of the report is just the first step in an elaborate licensing process, and "how this will move forward is a political question."

That's because next steps in the licensing process will require two important things. One is NRC funding for continuation of the licensing process, which the US Congress will have to appropriate. The other is an organization at the US Department of Energy (DOE) that will have to be put in place to carry through the licensing process. "Those are huge 'ifs,", McCullum said.

The United States has already spent 20 years and nearly $\$ 15$ billion developing the Yucca Mountain repository. The issue has been embroiled in political controversy since Congress chose the site in 1987 in an amendment to the 1982 Nuclear Waste Repository Act. In 2008,

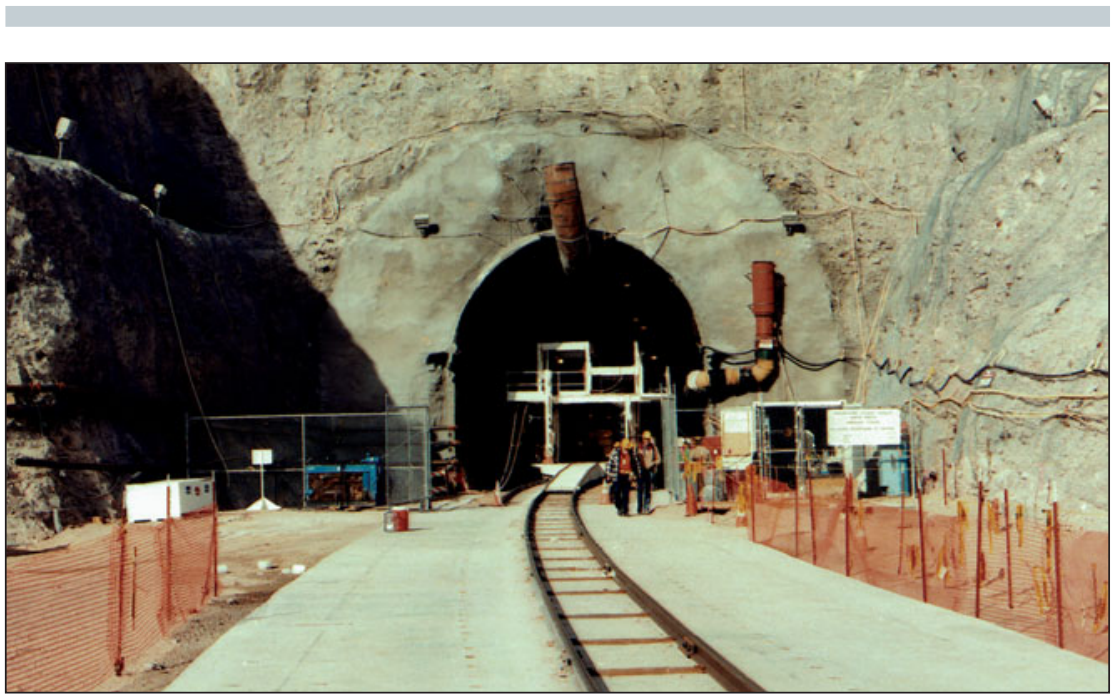

Entrance to Yucca Mountain under construction (Nov. 2007). Photo: Nuclear Regulatory Commission.

the DOE submitted a license application to the NRC to construct the repository. But the DOE withdrew its application and Congress terminated funding for the NRC's application review in 2010.

This led states and utilities storing spent fuel to sue the NRC. In August 2013, the federal court of appeals for the DC Circuit ordered the NRC to resume the licensing process using any available funds. The latest report is a result of that court order. Its publication does not mean that the NRC will authorize construction of the repository, but it nudges the licensing process forward. "It gives half a green light," McCullum said.

Next will come detailed, time-consuming hearings by the Atomic Safety Licensing Board (ASLB) on contentions raised by parties that are affected by the repository. Nearly 300 such contentions are already on file, over 200 of those by the state of Nevada. Once the ASLB arrives at a decision, it can be appealed through the NRC's commissioners, Ewing said. "Even after the commissioners have taken a position, it can still be appealed through the courts," he said.

For Volume 3, the NRC staff evaluated DOE's performance assessment that considered complex technical factors such as the evolution of the natural environment, degradation of engineered barriers, and disruptive events like seismic activity.

"There's no debate between the NRC and the DOE," McCullum clarifies. "I sat through many public meetings and watched dozens of NRC scientists intensely debate every single aspect of this. The only questions that remain are those that have been raised by opponents."

Many of the contentions are based on differences in scientific opinions, says Ewing. The application bundles a variety of studies that model hundreds of physical and chemical processes from the atomic scale to the scale of kilometers, and projects them out for hundreds of thousands of years. "There are many ways to handle models," Ewing said. "One can do calculations that bound a range of parameters making conservative assumptions. One can make more 
realistic assumptions, or do more deterministic evaluation of the process."

One small example is the debated discovery of the presence of the anthropogenic isotope chlorine-36 in the repository. High numbers indicate the movement of water into the repository from the surface. But concentrations are low enough to argue whether the isotope is even present. "So there is a clash between those who say we should use a reasonable number in models," said Ewing, "versus those that say we need more data to find out if the Cl-3w6 is really there and how it arrived at the repository level."
The NRC had released Volume 1 covering general information on the repository in 2010. It plans to release the other three volumes by January 2015 . Volume 2 is on repository safety before permanent closure, Volume 4 on administrative and programmatic requirements, and Volume 5 on license specifications. McCullum expects those to have "as affirmative a conclusion as Volume 3."

Meanwhile, the administration has also endorsed a separate three-step plan for waste disposal based on recommendations from a Blue Ribbon
Commission on America's Nuclear Future. The Commission called for a pilot interim storage facility, a larger interim facility, and finally a geological repository picked via a consent-based approach. "There are two parallel paths: what to do about Yucca Mountain and the broader recommendations from the BRC," Ewing said. "They will have to intersect at some point. This is a fascinating story of how materials science interacts with the social and political environments."

Prachi Patel
Minister Pandor unveils nanotech equipment at Rhodes University, South Africa

$\mathrm{S}$ cience and Technology Minister Naledi Pandor praised South Africa for becoming a major world player in cutting-edge nanotechnology despite only being involved for a short time.

Speaking at the launch of the new Rhodes University/Department of Science and Technology (DST) Centre for Nanotechnology Innovation last fall, Pandor said huge strides had been made since 2005, when South Africa took its first step entrenching this science by formulating a national strategy.

Pandor unveiled the center's time-offlight secondary ion mass spectrometer (TOF-SIMS), which will help the university focus on specialized cancer and microfiber research. The equipment is used by various departments at Rhodes University, as well as several other universities, the Council for Scientific and Industrial Research, and Mintek. It also serves countries as far afield as Kuwait, Turkey, and China.

Hosted in the Chemistry Department under the leadership of the DST/NRF South African Research Chairs Initiative Professor of Medicinal Chemistry and Nanotechnology, Tebello Nyokong, the TOF-SIMS examines thin films and provides surface compositions of these films, and studies the surface characteristics of nanoparticles. The examination of the surfaces using
TOF-SIMS impacts not only on layer interactions in development of sensors and drug delivery agents but in a wide range of disciplines where thin films are employed and where the immobilization thereof is critical to the success of the technologies being examined or developed, such as electronics, physics, geology, and biotechnology. In addition, the equipment could be used in the fields of pollution treatment, in green chemistry, forensic sciences, biotechnology, and could be geared toward energy and sustainable development. The cutting-edge equipment was purchased with a combined investment of $\mathrm{R} \$ 17$ million ( USD\$1.5 million) from Rhodes, the DST, and the National Research Foundation (NRF).

In 2005, the DST launched the National Nanotechnology Strategy, which aims to coordinate nano research and development at a national level around six focus areas including water, energy, health, chemical and bio-processing, mining and minerals, and advanced materials and manufacturing. Nanotechnology Innovation Centres are also located at the Council for Scientific and Industrial Research (CSIR) and Mintek.

Rhodes is a public research university located in Grahamstown in the Eastern Cape province of South Africa. The province also hosts the Ultra High Resolution Transmission Electron Microscopy Facility located at Nelson Mandela Metropolitan University (NMMU) in Port Elizabeth. According to Nyokong, the province has an important role to play in advancing the field. She said, "The news media will say [we're in] a poor province and nothing good will come out of it, that Rhodes is too small. For me those things are challenges. This equipment, together with the equipment at NMMU makes us the hub of Nanotechnology."

Pandor said, "The availability of the TOF-SIMS in the country will enhance the quality of research and training. The equipment will assist in advancing requirements to address the national skills shortage in many key areas of research."

The Minister spoke of how the 2005 National Nanotechnology Strategy had not only advanced the technology missions identified in the 2002 National Research and Development Strategy, but also strengthened government's industrial focus.

According to Pandor, the strategy has seen the adoption of a formal nanotechnology teaching program, nanotechnology research chairs, the production of 170 postgraduate students, and the publication of more than 1100 articles in peer-reviewed journals. In addition, more than 20 patents have been filed, and it is hoped that South Africandeveloped nanotechnology-enhanced products will soon enter the market. $\square$ 